\title{
Metabolic syndrome: what is it and what are the implications?
}

\author{
D. I. Shaw*, W. L. Hall and C. M. Williams \\ Hugh Sinclair Unit of Human Nutrition, School of Food Biosciences, University of Reading, Reading RG6 6AP, UK
}

\begin{abstract}
Obesity and overweight are linked with a cluster of metabolic and vascular disorders that have been termed the metabolic syndrome. Although there is not yet a universally-accepted set of diagnostic criteria, most expert groups agree that the syndrome is characterised by impaired insulin sensitivity and hyperglycaemia, dyslipidaemia (elevated blood triacyglycerols with depressed HDL-cholesterol), abdominal obesity and hypertension. Based on existing published criteria estimates suggest that the syndrome affects a substantial percentage of the middle-aged and elderly populations of most European countries (10-20\%) and confers increased risk of type 2 diabetes (2-8.8-fold) and CVD (1.5-6-fold), as well as having a marked effect on morbidity. Although the pathophysiology is incompletely understood, insulin resistance and abdominal obesity are central to subsequent abnormalities in circulating glucose and lipoproteins, and vascular function that lead to type 2 diabetes, atherosclerosis and CVD. The link between metabolic syndrome, type 2 diabetes and CVD, as well as inability to reverse the present rising rates of obesity, will lead to economically-unsustainable costs of health care in the next 10-20 years. Preventative strategies for metabolic syndrome are required to slow rates of progression and to reduce dependence on costly medical management. A notable development is recent evidence that shows that diet and exercise are more effective than drug treatment in preventing the development of type- 2 diabetes in high-risk individuals. The LIPGENE project will investigate dietary fat quality as a strategy for the prevention of metabolic syndrome and identify food chain approaches that can support consumer attempts to alter their dietary patterns.
\end{abstract}

Metabolic syndrome: Prevalence: Gender: Pathophysiology: Definition

\section{Metabolic syndrome: a multi-faceted disorder}

The term metabolic syndrome (or syndrome $\mathrm{X}$ ) was first put forward by Reaven (1988) to describe a cluster of disorders linked with obesity and hyperinsulinaemia, and associated with a markedly increased risk of type 2 diabetes and CVD. Current escalation in the global prevalence of obesity has led to renewed interest in this disorder and its implications for future rates of diabetes and CVD. Although a number of different sets of diagnostic criteria have been proposed for the metabolic syndrome (World Health Organization, 1999 (WHO criteria); Expert Panel on Detection, Evaluation, and Treatment of High Blood Cholesterol in Adults, 2001 (National Cholesterol Education Program (NCEP) criteria); European Group for the Study of Insulin Resistance,
2002), insulin resistance, hyperglycaemia, dyslipidaemia, central obesity and hypertension are generally agreed to be the five key features. However, these features are often accompanied by other related abnormalities of vascular function and lipoprotein metabolism (see Fig. 1). Most definitions require fulfilment of three of five key criteria, allowing for various spectra of presentation of the metabolic syndrome. Many authorities express the view that insulin resistance is the central pathological link amongst these risk factors, whilst other authorities believe that the metabolic syndrome is a consequence of the complications caused by obesity (Grundy, 2004a). Although central obesity is strongly associated with insulin resistance, it is clear that insulin resistance only occurs in approximately half of obese subjects (Nestel, 2004).

\footnotetext{
Abbreviations: NCEP, National Cholesterol Education Program; NCEP criteria, diagnostic criteria for the metabolic syndrome proposed by the NCEP Adult Treatment Panel III (Expert Panel on Detection, Evaluation, and Treatment of High Blood Cholesterol in Adults, 2001); TAG, triacylglycerols; TRL, TAG-rich lipoprotein; WHO criteria, diagnostic criteria for the metabolic syndrome proposed by the World Health Organization (1999). *Corresponding author: Ms D. Shaw, fax +441189318703, email d.i.shaw@reading.ac.uk
} 


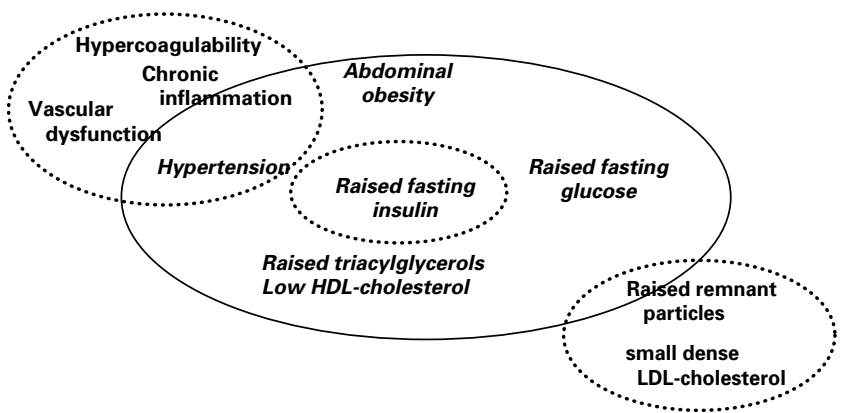

Fig. 1. Diagrammatic representation of the main features of the metabolic syndrome.

\section{Insulin resistance and the disorders of the metabolic syndrome}

Whether insulin resistance is the primary event in the development of the metabolic syndrome or arises as a consequence of obesity, it is clear that insulin resistance is an important factor in the associated disturbances in carbohydrate and lipid metabolism. In the metabolic syndrome, as in type 2 diabetes, the response to insulin is impaired, resulting in a compensatory hyperinsulinaemia. Over a period of time hyperinsulinaemia fails to compensate for impaired insulin action on glucose uptake and metabolism, with resulting hyperglycaemia. Although insulin is commonly recognised as a hormone involved in glucose metabolism, this hormone also has a critical role in lipid metabolism. Resistance to the actions of insulin on lipid metabolism underlies the typical dyslipidaemia of the metabolic syndrome, which is characterised by moderately-elevated blood triacylglycerols (TAG) and reduced HDL concentrations. Elevated circulating TAG are a result of an increase in TAG and VLDL synthesis and secretion from the liver. There is also reduced systemic clearance of TAG as a result of impaired insulin-mediated activation of lipoprotein lipase. This enzyme normally hydrolyses TAG in circulating chylomicrons and VLDL and enables uptake of fatty acids into peripheral tissues. It is therefore not surprising to observe that in addition to abnormalities in fasting lipoprotein concentrations there are marked elevations in circulating postprandial TAG concentrations following a fat-containing meal in individuals with the metabolic syndrome. This effect is frequently referred to as the TAG intolerance of metabolic syndrome and resembles the glucose intolerance observed when large carbohydrate doses are given to subjects with insulin resistance.

Insulin normally suppresses the activity of hormonesensitive lipase, the enzyme that hydrolyses intracellular TAG in adipose tissue, leading to sustained release of fatty acids into the circulation and raised circulating NEFA levels. Hormone-sensitive lipase is elevated under fasted conditions and reduced under fed conditions as a result of inhibition by insulin. However, in insulin-resistant subjects hormone-sensitive lipase activity is not fully suppressed in the fed state and NEFA levels are elevated. Elevated NEFA have various deleterious effects (including stimulation of hepatic TAG and VLDL synthesis and competitive inhibition of peripheral tissue uptake of glucose) that further exacerbate insulin resistance-related glucose intolerance.

In the metabolic syndrome LDL concentrations may be normal, but the proportion of LDL as small dense LDL is increased; HDL-cholesterol concentrations are lower than normal but the proportion of small dense HDL is also increased. These qualitative abnormalities in circulating lipoproteins are a result of accelerated serum neutral-lipid exchange, mediated by a cholesteryl ester transfer protein and stimulated by the raised concentrations of TAG-rich lipoprotein (TRL) particles. Net transfer of TAG from TRL to HDL and LDL particles is promoted under these conditions; this process is followed by TAG hydrolysis on LDL and HDL, which results in formation of small dense cholesterol-rich particles. Small dense LDL particles are not effectively removed by the LDL receptor, are retained longer within the circulation and have a greater potential to infiltrate the artery wall. Small dense HDL is more rapidly catabolised than more buoyant HDL; over a period of time the accelerated catabolism of HDL particles leads to the low circulating HDL concentrations that typify the insulinresistant subject. This collection of circulating lipoprotein abnormalities (low HDL, moderately-raised fasting TAG, elevated TRL remnant concentrations and raised small dense LDL) are referred to as the atherogenic lipoprotein phenotype, which when present confers a 2-5-fold increased risk of CVD (Cefalu, 2001; Cunnane \& Griffin, 2002).

Hypertension is a common feature of the metabolic syndrome that has been explained by increased activity of the sympathetic nervous system as a result of hyperinsulinaemia. Furthermore, hypertriacylglycerolaemia, a key component of insulin-resistant dyslipidaemia, has been implicated in the endothelial dysfunction that occurs in insulin-resistant subjects. Raised TRL particles may lead to impaired-flow-mediated dilation, a vascular response that is critical to maintaining normal blood pressure. The mechanism for the effect of TRL is unclear, but may involve the production of reactive oxygen species and vasoactive molecules that could interact with endothelial NO-mediated vasodilation (van Oostrom et al. 2002). Importantly, adverse effects on blood flow and on endothelial function, secondary to insulin resistance, have the potential to further impair the transport of glucose and TRL to sites of their normal storage and utilisation, therefore heightening the states of dyslipidaemia and hyperglycaemia (Cefalu, 2001; van Oostrom et al. 2002).

The metabolic syndrome may also be characterised by the presence of pro-inflammatory conditions, microalbuminuria and hypercoagulability (World Health Organization, 1999). The Framingham Offspring Study (Wilson, 2004) has shown that haematological abnormalities, such as raised prothrombotic plasminogen activator inhibitor type 1 , tissue plasminogen activator and fibrinogen, are associated with hyperinsulinaemia and hyperglycaemia. Studies (Cefalu, 2001) have also shown that improvement in insulin resistance is paralleled by improved metabolic abnormalities and by return of these haematological factors towards normal. 
Table 1. Definitions of the metabolic syndrome: global, US and Europe

\begin{tabular}{|c|c|c|}
\hline NCEP ATP III* & WHO† & EGIR $\ddagger$ \\
\hline Three of the following: & $\begin{array}{l}\text { Diabetes or impaired glucose tolerance } \\
\text { or insulin resistance (under clamp } \\
\text { conditions) and two of the following: }\end{array}$ & $\begin{array}{l}\text { (Definition for non-diabetics only) } \\
\text { Insulin resistance or fasting hyperinsuli- } \\
\text { naemia and two of the following: }\end{array}$ \\
\hline $\begin{array}{l}\text { 1. Fasting plasma glucose } \\
\geq 6 \cdot 1 \mathrm{mmol} / \mathrm{l}(\geq 11.0 \mathrm{mg} / \mathrm{l})\end{array}$ & $\begin{array}{l}\text { 1. Microalbuminuria } \\
\text { Urinary albumin excretion rate } \\
\geq 20 \mu \mathrm{g} / \mathrm{min} \text { or } \\
\text { Albumin:creatinine } \geq 30 \mathrm{mg} / \mathrm{g}\end{array}$ & 1. Fasting plasma glucose $\geq 6.1 \mathrm{mmol} / \mathrm{l}$ \\
\hline $\begin{array}{l}\text { 2. Central obesity } \\
\text { Waist circumference }>1020 \mathrm{~mm} \\
\text { (men), >880 mm (women) }\end{array}$ & $\begin{array}{l}\text { 2. Central obesity } \\
\mathrm{BMl}>30 \mathrm{~kg} / \mathrm{m}^{2} \text { and } / \mathrm{or} \\
\mathrm{WHR}>0.9 \text { (men), }>0.85 \text { (women) }\end{array}$ & $\begin{array}{l}\text { 2. Central obesity } \\
\text { Waist circumference } \geq 940 \mathrm{~mm} \\
\text { (men), } \geq 800 \mathrm{~mm} \text { (women) }\end{array}$ \\
\hline $\begin{array}{l}\text { 3. Hypertension } \\
\text { Blood pressure } \geq 130 / 85 \mathrm{mmHg}\end{array}$ & $\begin{array}{l}\text { 3. Hypertension } \\
\text { Blood pressure }>140 / 90 \mathrm{mmHg}\end{array}$ & $\begin{array}{l}\text { 3. Hypertension } \\
\text { Blood pressure } \geq 140 / 90 \mathrm{mmHg} \text { and/or } \\
\text { Medication }\end{array}$ \\
\hline $\begin{array}{l}\text { 4. Hypertriglyceridaemia } \\
\text { Triacylglycerols } \geq 1.7 \mathrm{mmol} / \mathrm{l} \\
\mathrm{HDL}<1.0 \mathrm{mmol} / / \mathrm{l} \text { (men), } \\
<1.3 \mathrm{mmol} / \mathrm{l} \\
\text { (women) }\end{array}$ & $\begin{array}{l}\text { 4. Dyslipidaemia } \\
\text { Triacylglycerols }>1.7 \mathrm{mmol} / \mathrm{l} \text { and/or } \\
\mathrm{HDL}<0.9 \mathrm{mmol} / \mathrm{l} \text { (men), } \\
<1.0 \mathrm{mmol} / \mathrm{l} \text { (women) }\end{array}$ & $\begin{array}{l}\text { 4. Dyslipidaemia } \\
\text { Triacylglcerols }>2.0 \mathrm{mmol} / \mathrm{l} \\
\text { or } \\
\mathrm{HDL}<1.0 \mathrm{mmol} / \mathrm{l} \\
\text { or } \\
\text { Treated for dyslipidaemia }\end{array}$ \\
\hline
\end{tabular}

NCEP ATP III, National Cholesterol Education Programme Adult Treatment Panel III; WHR, waist: hip ratio; EGIR, European Group for the Study of Insulin Resistance.

*Expert Panel on Detection, Evaluation, and Treatment of High Blood Cholesterol in Adults (2001).

†World Health Organization (1999).

łEuropean Group for the Study of Insulin Resistance (2002) and Balkau \& Charles (1999).

\section{Definitions of the metabolic syndrome}

Given the number of systems affected and the wide interindividual variability observed, it is not surprising that currently there is no universally-accepted definition of the metabolic syndrome. A universal definition for metabolic syndrome would enable more effective clinical diagnosis and allow global monitoring for the purpose of policy development and establishment of prevention programmes.

The NCEP Adult Treatment Panel III (Expert Panel on Detection, Evaluation, and Treatment of High Blood Cholesterol in Adults, 2001), the World Health Organization (1999) and the European Group for the Study of Insulin Resistance (2002) have each defined the metabolic syndrome (Table 1). Each of the definitions includes a measure of obesity or central obesity, hypertension and dyslipidaemia. Insulin resistance is the main focus of the WHO criteria, whereas the NCEP definition (Expert Panel on Detection, Evaluation, and Treatment of High Blood Cholesterol in Adults, 2001) does not include a direct measure of insulin resistance. The World Health Organization (1999) definition allows inclusion of individuals with diabetes, whereas this condition is not included in the other definitions discussed.

The inclusion of microalbuminuria has been questioned as a core component of the World Health Organization (1999) definition, as it is not usually present in individuals without diabetes (Laaksonen et al. 2002). Further points of discussion include the methods of measurement and the cutoff points used to define abnormality. The reliability and clinical applicability of measurements of insulin resistance has been widely debated. The most appropriate measure of central obesity, e.g. the use of waist:hip ratio or waist circumference, has been discussed in light of the fact that waist: hip ratio correlates with disease end points independently of waist measurement and BMI, whereas waist measurement correlates better with visceral fat deposits as measured by tomography (Laaksonen et al. 2002). The use of gender-specific cut-offs for abdominal obesity and HDL has also been questioned because a French longitudinal cohort study (Balkau et al. 2003) and the National Health and Nutrition Examination Survey III (Ford et al. 2002) have shown that risk for CVD increases with central adiposity independently of gender (Balkau et al. 2003).

A factor that needs urgent consideration is the inclusion of cut-off thresholds that take into account the differential susceptibility of ethnic subgroups such as AfricanAmericans or the Asian population. Metabolic syndrome and its associated disease outcomes are highly prevalent in these groups, but current cut-off points may underestimate true prevalence, with an adverse consequence for prevention programmes. Tan et al. (2004) have investigated the use of the NCEP criteria in an Asian population using data from a cross-sectional national health survey involving 4723 men and women. They have proposed that the adverse impact of central obesity on insulin sensitivity occurs at a lower waist circumference in Asian groups than in Caucasian groups, and recommend the use of a lower cut-off value to reflect this difference.

\section{Insulin resistance and abdominal obesity in the aetiology of the metabolic syndrome}

The pathophysiology of the metabolic syndrome is poorly understood, largely because the close interrelationship 
between insulin resistance, obesity and lipid abnormalities precludes a clear identification of the primary pathological event(s). It has been suggested that a defect in the insulin signalling pathway may be a key mechanism in the development of the metabolic syndrome, particularly within specific tissues such as the liver, adipose tissue and muscle (Kohen-Avramoglu et al. 2003). However, there are also data that suggest that the defects in insulin signalling are secondary to intracellular disturbances of carbohydrate and lipid utilisation in tissues, and that these disturbances arise when energy balance and body weight are disturbed. A better understanding of the pathophysiology of insulin resistance, and of the metabolic syndrome, would allow identification of predictive risk factors and enable effective dietary and lifestyle interventions to be devised.

Using traditional epidemiological approaches to disentangle the contribution of insulin resistance and central obesity to the development of the metabolic syndrome has proved to be extremely difficult, because these two factors are themselves so closely interlinked. The Bogalusa Heart Study (Chen et al. 1999) has investigated the prevalence of the metabolic syndrome amongst young parents and their offspring. The odds ratio for offspring having the same cluster of metabolic syndrome components as their father, mother, and both parents was found to be $7 \cdot 2,8.6$ and $7 \cdot 9$ respectively. Furthermore, adverse parental insulin levels and BMI were shown to markedly increase the risk of their offspring developing metabolic syndrome. However, the risk attributed to parental insulin levels was found to be reduced when adjustment is made for parental BMI. This study has not only confirmed a familial trait for the metabolic syndrome but also suggests that parental obesity, and thereby associated hyperinsulinaemia in parents, may underlie this familial association.

There is substantial evidence from epidemiology to support the link between insulin resistance and the metabolic syndrome. In the Strong Heart Study (Resnick et al. 2003) non-diabetic American Indians ( $n$ 2283) were followed over 7.7 (SD 1.8) years and the prevalence of metabolic syndrome (NCEP definition; Expert Panel on Detection, Evaluation, and Treatment of High Blood Cholesterol in Adults, 2001) was found to increase markedly with the homeostasis model assessment of insulin resistance score. Weiss et al. (2004) have also shown that the prevalence of metabolic syndrome increases with insulin resistance, after adjustment for race, ethnic group and extent of obesity. Furthermore, in the Bruneck Study (Bonora et al. 2003) the number of components of the metabolic syndrome was found to increase with the extent of insulin resistance. Similarly, the decrease in the number of criteria of metabolic syndrome with a $1 \mathrm{SD}$ improvement in insulin sensitivity is associated with an odds ratio of 0.51 . In a meta-analysis of eleven studies the clustering of risk factors for the metabolic syndrome was found to increase with quartiles of fasting insulin levels, with a marked increase in clustering within the highest quartile of insulin resistance (Carr et al. 2004; $\mathrm{Hu}$ et al. 2004). These findings highlight the role of insulin resistance as a central component of the metabolic syndrome.
There are similarly strong data to support the role of obesity, and in particular abdominal obesity, in metabolic syndrome. A cross-sectional study in Spain ( $n$ 283; Ascaso et al. 2003) has found that the prevalence of the metabolic syndrome is significantly increased $(P<0.001)$ in subjects with abdominal obesity (defined as a waist circumference of $>880 \mathrm{~mm}$ in women and $>1020 \mathrm{~mm}$ in men); insulin resistance is also more prevalent in individuals with abdominal obesity. A waist circumference of $>890 \mathrm{~mm}$ in women and $>1020 \mathrm{~mm}$ in men has been classed as the optimal predictor of the metabolic syndrome in the Insulin Resistance Atherosclerosis Study (Palaniappan et al. 2004), a prospective study that included subjects of various ethnic backgrounds ( $n 714$, average 5-2-year follow-up), with logistic regression models adjusted for age, sex, study site, ethnicity and impaired glucose tolerance showing an odds ratio of $1 \cdot 7 / 110 \mathrm{~mm}$ increase in waist circumference. Interestingly, impaired glucose tolerance was not found to be a useful predictor of the metabolic syndrome. These prospective data support the view that obesity precedes the development of the metabolic syndrome, although the fact that the study was not population based suggests that extrapolation to the general population should be done with some caution. Carr et al. (2004) have found that intraabdominal fat and subcutaneous fat levels (measured by single-slice computer tomography) are higher in those subjects with the metabolic syndrome. Indeed, a strong positive correlation was found between intra-abdominal fat area and the number of criteria of the metabolic syndrome, with associated odds ratios of 2.1 and 1.97 for intraabdominal fat and subcutaneous fat respectively. It is noteworthy that these associated odds ratios for abdominal and subcutaneous fat areas were shown to be greater than the odds ratio associated with a decrease in insulin resistance. Importantly, waist circumference was found to be more strongly correlated with intra-abdominal fat area $(r$ 0.799) than with subcutaneous fat area $(r 0.595)$. It is argued (Carr et al. 2004) that criteria for the metabolic syndrome should include measurement of waist circumference, which ensures that intra-abdominal fat area, a factor found to be independently associated with all criteria, is appropriately weighted in the diagnosis.

Although the epidemiological studies clearly show that both insulin resistance and obesity have clear associations with the metabolic syndrome, such data are unable to identify the causal pathway. The study carried out by Carr et al. (2004) shows that both insulin resistance and abdominal obesity are correlated with the metabolic syndrome. However, the authors suggest that as intraabdominal fat is independently associated with all criteria, visceral adiposity may have a particular role in the pathophysiology of the metabolic syndrome. The role of adipose tissue, and of specific adipose tissue depots, in the disturbances of insulin and macronutrient metabolism in obesity is an exciting area of current research. Bioactive products of the adipocyte, such as TNF $\alpha$, IL- 6 and leptin, and reduced concentrations of adiponectin have been implicated in the aetiology of insulin resistance. The product of adipose tissue TAG hydrolysis, NEFA, also appears to play a primary role in disturbances in wholebody glucose and lipid metabolism (Grundy, 2004b). 
A detailed discussion of adipose tissue biology and of the role of NEFA in insulin resistance and metabolic syndrome is beyond the scope of the present review. However, examination of these issues is provided by a number of recent reviews (Haber et al. 2002; Kraegen et al. 2002).

\section{Prevalence of the metabolic syndrome}

The incidence of obesity is rapidly increasing in the USA and Europe, and increases in obesity are also now being observed in developing countries (World Health Organization/Food and Agriculture Organization, 2003). It has been estimated that up to $80 \%$ of the 45-59-year-olds in eastern Europe may be obese, with the greatest prevalence being amongst women (James, 2004). Globally, $10 \%$ of the school-age children are overweight, with approximately $3 \%$ of these being clinically obese (Lobstein et al. 2004). The rapid rate of increase is of major concern. In parts of Europe an additional $1 \%$ of the children are becoming overweight each year (Lobstein et al. 2004). Indeed, throughout Asia, Latin America and parts of Africa, where previously there has been widespread undernutrition, obesity has increased 2-3-fold in the past decade (World Health Organization/Food and Agriculture Organization, 2003).

The risk of developing type 2 diabetes is up to 10 -fold greater in those individuals with a BMI $>30 \mathrm{~kg} / \mathrm{m}^{2}$ (Diabetes UK, 2004), and the current rise in obesity amongst children and adults is generating a worldwide epidemic of type 2 diabetes. Since 1996 the number of individuals diagnosed with diabetes in the UK has increased from 1.4 million to 1.8 million in 2004 , with projections that it will reach three million by 2010 (Diabetes UK, 2004). The present rates of increase in obesity, and of type 2 diabetes, are indicative of an increased prevalence of metabolic syndrome. The need to confirm and quantify the accuracy of this prediction is of considerable importance, because of the high predictive value of metabolic syndrome for CVD and diabetes.

The lack of a universally-accepted definition is a limiting factor in attempts to quantify present rates of metabolic syndrome and the likely prevalence in the future. Estimates of prevalence vary considerably depending on the criteria used (Table 1). In one study of the same adult Finnish population the prevalence rates were reported to vary from $8.8 \%$ to $14.3 \%$, depending on the definition used (Lakka et al. 2002). Fig. 2 provides a summary of prevalence rates recorded in recent European and US studies. Clearly, these studies indicate a greater prevalence of metabolic syndrome in the US population as compared with the European population, and this finding is consistent with the higher rates of obesity in the USA. However, the quality and consistency of the studies vary considerably and it is important to consider the types of populations included in these studies. The Spanish study (Ascaso et al. 2003) indicates a high prevalence rate $(28.9 \%)$ in comparison with the other European studies (8·1-19.8\%). However, the subjects were at greater risk than the general population since they were recruited from a primary care outpatient unit and the definition used to diagnose metabolic syndrome could be considered to lack rigour since only two criteria were required to be fulfilled.

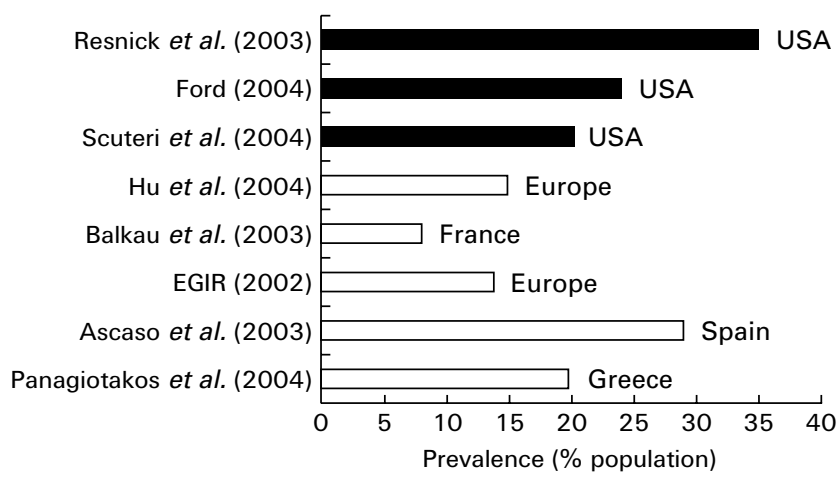

Fig. 2. Prevalence (\%) of metabolic syndrome in US (ם) and European ( $\square$ ) adults. EIGR, European Group for the Study of Insulin Resistance.

The majority of the studies that have been reviewed confirm that independently of the criteria used the incidence of metabolic syndrome increases with age. Most studies that aim to assess the population incidence of the metabolic syndrome usually include adult subjects $>18$ years of age, although many studies use the 25-30 years age-range as the lower limit for inclusion. Importantly, the Bogalusa Heart Study has shown that the metabolic syndrome is present in children and young adults (Chen et al. 1999). Indeed, in a large group of multi-ethnic multiracial 4-20-year-olds, using both the NCEP (Expert Panel on Detection, Evaluation, and Treatment of High Blood Cholesterol in Adults, 2001) and World Health Organization (1999) definitions, the metabolic syndrome was shown to be present in 38.7 and $49.7 \%$ of moderately- and severely-obese groups respectively (Weiss et al. 2004). Within the EU fourteen million children are overweight, which includes three million obese children, and the epidemic of childhood obesity and overweight is accelerating. Currently, $10-20 \%$ of the children in northern Europe are overweight compared with a prevalence of 20-35\% in southern Europe (International Obesity Task Force, 2004).

These statistics for children illustrate that in the future prevalence rates for metabolic syndrome are likely to be even higher than present rates in adult populations. Clearly, the inclusion of younger age-groups in population studies would result in an underestimation of overall prevalence in older age-groups. However, further studies in children and young adults are urgently required as a means of assessing the likely impact of rising rates of overweight and obesity on the metabolic syndrome in the future. A further point to consider is the use of age-truncated rates (35-65 years) to assess prevalence rates. Many studies include subjects only up to the age of approximately 65 years and thereby underestimate the true impact of metabolic syndrome in later years. With increasing life expectancy and many of the population living into their 8th decade, the present data underestimate the impact of lifestyle-related metabolic disturbance on human health and the likely future costs of health care.

There are marked ethnic variations in susceptibility to the metabolic syndrome. Prevalence amongst American Indians, for example, is estimated at 35\% which is much 
greater than estimates for other groups (Resnick et al. 2003). Additionally, Tan et al. (2004) have proposed that present cut-off points for waist circumference or BMI are likely to underestimate true prevalence rates in Asian Indians. Similarly, cut-offs for blood lipid profiles may give a false indication of lower rates of the metabolic syndrome for some groups, since black populations generally show more favourable lipid profiles than white populations relative to their actual risk of the metabolic syndrome (Weiss et al. 2004). In the study of Weiss et al. (2004), when data that account for the more favourable lipid profiles of black subjects are used, the prevalence of the metabolic syndrome and effect of obesity on risk are similar amongst the various races studied.

There is a lack of reliable population data on prevalence rates for metabolic syndrome from the developing world, but the data for obesity and diabetes are strongly suggestive of a growing incidence of the metabolic syndrome in these parts of the world. A factor that may predispose to even higher rates of obesity and type 2 diabetes in populations previously exposed to undernutrition is the presence of a 'thrifty genotype'(Dowse \& Zimmet, 1993; Kohen-Avramoglu et al. 2003). In societies in which food supply has been insecure, it is suggested that genotypes with the capacity to store large amounts of fat during times of plentiful supply will have tended to survive at the expense of less-thrifty genotypes. Thus, biological mechanisms that enable individuals to store fat will tend to be overrepresented in such societies, and during times of plentiful food supply will lead to greater capacity to become obese (Kohen-Avramoglu et al. 2003).

Many of the current findings for prevalence rates of metabolic syndrome are based on data from ongoing prospective studies of large European or American populations. Most of them were not initially set up to measure indicators of insulin sensitivity or central body fat distribution, and consequently many of the studies have used modified versions of the established risk factor criteria. More studies are needed that incorporate measurements in both sexes, high-risk ethnic groups and younger and older subjects and adhere to standardised criteria, using adjusted cut-off points where relevant.

\section{The implications of the metabolic syndrome: CVD and type 2 diabetes}

There is mounting evidence to suggest that the presence of the metabolic syndrome increases individual risk of type 2 diabetes and CVD, major causes of morbidity and mortality.

In a male Finnish population four definitions for the metabolic syndrome based on the WHO and NCEP criteria were used to assess the progression of the metabolic syndrome to type 2 diabetes. After a 4-year follow-up the odds ratio range for risk imposed by the metabolic syndrome was found to be $5 \cdot 0-8 \cdot 8$. The WHO criteria predicted a 9-fold increased risk of development of type 2 diabetes for individuals with the metabolic syndrome. It was concluded that type 2 diabetes is closely related to the metabolic syndrome and could be considered an end-stage manifestation of the metabolic syndrome (Laaksonen et al.

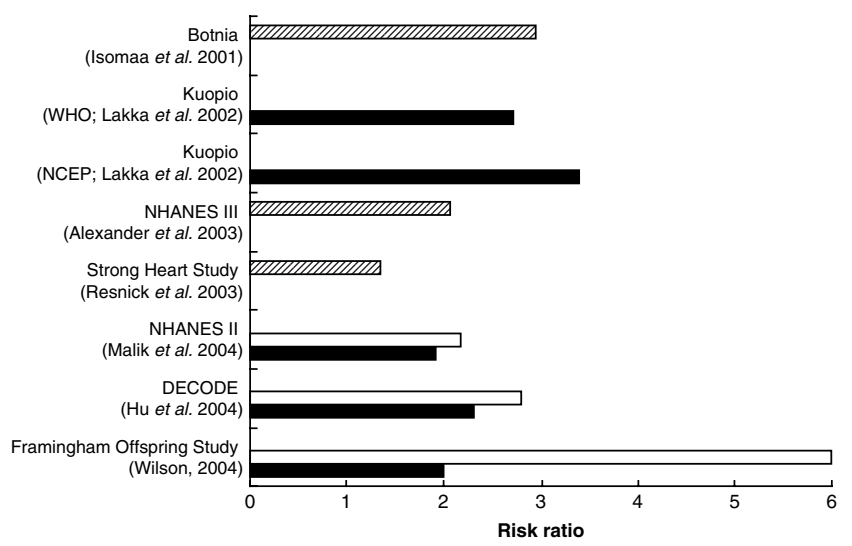

Fig. 3. Impact of the metabolic syndrome on rates of cardiovascular and heart disease. ( $\square)$, Men; $(\square)$, women; $(\mathbb{Z})$, combined men and women. NHANES III, National Health and Nutrition Examination Survey III; DECODE, diabetes epidemiology: collaborative analysis of diagnostic criteria in Europe. WHO, World Health Organization (1999) criteria; NCEP, National Cholesterol Education Program Adult Treatment Panel III (Expert Panel on Detection, Evaluation, and Treatment of High Blood Cholesterol in Adults, 2001) criteria; for details of these two sets of criteria, see Table 1.

2002). In a prospective study of Pima Indians ( $n$ 1918; Hanson et al. 2002) with a median follow-up of $4 \cdot 1$ years the WHO criteria were found to be more sensitive and more specific at predicting development of type 2 diabetes than the NCEP criteria. The metabolic syndrome as defined by WHO criteria was found to confer a greater risk of progression to type 2 diabetes (odds ratio 3.58) than the NCEP criteria (odds ratio 2.09). This difference is likely to be a result of the emphasis in the WHO definition on presence of insulin resistance, compared with the NCEP definition that weights all components equally.

Although the link with type 2 diabetes is well established, the additional risk for CVD and CHD remains to be quantitatively established. A number of prospective studies that have assessed the outcome for CVD and CHD provide odds ratio estimates of between 1.5 and 6.0 in subjects who fulfil the criteria for metabolic syndrome (Fig. 3). As previously discussed, estimates of the impact on CVD will depend on the rigour of the criteria used to confer classification of metabolic syndrome. Fig. 3 shows that the odds ratios for CVD and CHD in individuals with the metabolic syndrome differ when the WHO $(2 \cdot 72)$ and NCEP (3.40) definitions are used in the same Finnish male study population (Lakka et al. 2002), although both clearly demonstrate an extent of risk that has an important public health impact. It is clear that the major public health focus should be to emphasise the powerful impact of the clustering of the five components of metabolic syndrome (insulin resistance, hyperglycaemia, dyslipidaemia, central obesity and hypertension) (Isomaa et al. 2001). Factor analysis has shown that there is an interdependence of the components and their clustering does not occur by chance (Nestel, 2004).

Data from studies that have investigated the effects of gender suggest that the presence of metabolic syndrome may confer a greater cardiovascular risk in women than in 
men. In particular, the Framingham Offspring Study has shown that the increased risk for women rises sharply when three or more symptoms of the metabolic syndrome are present, with an odds ratio of $5 \cdot 0$ for women compared with 2.0 for men (Wilson, 2004). Data for rates of myocardial farction and stroke from the National Health and Nutrition Examination Survey III also show that women have a higher risk of these conditions than men when criteria for the metabolic syndrome are fulfilled (Ninomiya et al. 2004). There is a need to understand potential mechanisms that underlie the greater impact of metabolic syndrome on vascular function in women, and further epidemiological studies are required to confirm and quantify the extent of the additional risk. From these data it would appear that an important public health message is failing to be adequately addressed in current health promotion programmes. Lack of recognition of the problem amongst health professionals is an important factor determining the present inaccurate perception of women as a relatively-low-risk group for CVD and CHD.

The risk to human health of the rising tide of obesity, overweight and the metabolic syndrome is further emphasised when data on children is reviewed. A preliminary follow up (21.5 (SD 10.5) months) of overweight and obese children (Weiss et al. 2004) has shown that within this short time frame $24 \%$ of the children with the metabolic syndrome at baseline developed type 2 diabetes. In the future the effects of cumulative overweight and obesity, tracked from childhood to adulthood, are likely to result in a marked escalation of the current situation, which is based on the relatively short-term impacts of adult obesity on later health.

There clearly needs to be greater awareness of the metabolic syndrome amongst health professionals. Until this situation is achieved the present lack of awareness of the problem amongst the general population will not be rectified. In a study of a high-risk group in Greece $78 \%$ of the men and $74 \%$ of the women with the metabolic syndrome were found to be unaware of their condition; furthermore, they were not aware of its importance to their risk of chronic diseases (Panagiotakos et al. 2004).

There is an urgent need for more robust data on prevalence rates and impact on risk for type 2 diabetes and CVD. The study of the relationship between insulin sensitivity and CVD risk conducted by the European Group for the Study of Insulin Resistance (Hills et al. 2004) is an ongoing European multi-centre prospective study ( $n$ 1500, subjects of 30-60 years of age, across thirteen countries) that will provide important data for the development of a better understanding of insulin resistance, metabolic syndrome and CVD risk.

\section{Future approaches to the metabolic syndrome}

Although present data make it difficult to provide a precise estimate of the prevalence of the metabolic syndrome, there is little doubt that prevalence is increasing and that there are adverse impacts on human health. The present review has mainly emphasised the relationship between the metabolic syndrome and mortality rates for CVD, because mortality data is more readily available than other markers of health outcome. Morbidity caused by associated conditions such as eye disease, stroke risk, kidney problems and nerve damage, which have adverse impacts on the quality of life of individuals with diabetes and on the costs of health care, are less easily quantified. However, current estimates indicate that in the UK $£ 3.5 \times 10^{9}$ year is spent on the treatment of diabetes and its complications alone, and expenditure is expected to rise by $10 \%$ by 2011 (Diabetes UK, 2004).

Although rates of obesity have quadrupled in many developed countries over the past 25 years, it is highly unlikely (even with the most extreme public health interventions) that present rates of obesity can be reversed in the same time period. Efforts to introduce lifestyle changes to reduce current rates of obesity and slow down the rate at which obesity is increasing in the developed and developing world must be stepped up. However, more achievable short-term measures that can reduce the adverse impact of obesity on human health must also be considered. A first step could be interventions to reduce the prevalence of metabolic syndrome. Although there are some difficulties in arriving at a precise definition of the metabolic syndrome, efforts in this direction should be encouraged, since a robust definition could provide a target for intervention in the public health programmes that must be mounted in the near future.

Further research is also needed to assess qualitative and quantitative changes in diet that could reduce the impact of overweight and obesity on metabolic syndrome and insulin resistance. An area of great interest is the impact of dietary fat quality on markers of the metabolic syndrome and the associated insulin resistance. The KANWU study ( $n$ 162; Vessby et al. 2001), one of few human studies to have investigated this area, has found that diets rich in MUFA reduce the adverse effects of diets rich in saturates on insulin sensitivity, although beneficial effects are only seen in diets that provide $<37 \%$ energy as fat. Further studies are required to confirm these findings and understand the mechanisms involved. LIPGENE is a multi-centred 5-year pan-European project that will study the impact of dietary fat quality and of diet-sensitive genotypes on insulin sensitivity and on risk markers for the metabolic syndrome. Further details of the project are given in accompanying papers in this symposium and can be accessed via www.lipgene.tcd.ie and www.nutrition. org.uk. Studies of the effects of dietary carbohydrate quality, alcohol and achievable exercise regimens on insulin sensitivity are also urgently required. The capability to provide a more individualised approach to diet and lifestyle interventions would also be aided by a better understanding of the interrelationships between diet composition and individual genotypes, and the implications of such interactions on markers of the metabolic syndrome.

\section{Conclusions}

The prevalence of metabolic syndrome is already high in middle-aged and elderly populations in Europe, and rates are increasing rapidly as a consequence of the predominance of overweight and obesity in most developed 
countries. Metabolic syndrome represents an important public health problem, which if left unaddressed has the potential to overwhelm the provision of effective health care in Europe. In the long term the present rise in rates of obesity must be halted and reversed. In the meantime qualitative changes in diet provide a mechanism for reducing the impact of obesity on insulin resistance and metabolic syndrome. Research into the efficacy, mechanisms and means of achieving consistent dietary change is urgently needed.

\section{Acknowledgements}

This work was supported by funding from the European Commission, Framework Programme 6 (contract no. FOOD-CT-2003-505944). The authors would also like to thank other members of the LIPGENE team at the University of Reading, Dr Julie Lovegrove, Dr Rachel Gitau and Dr Anne-Marie Minihane for their stimulating discussions.

\section{References}

Alexander C, Landsman P, Teutsch S \& Haffner S (2003) NCEPdefined metabolic syndrome, diabetes and the prevalence of coronary heart disease among NHANES III participants age 50 years and older. Diabetes 52, 1210-1214.

Ascaso J, Romero P, Real J, Lorente R, Martinez-Valls J \& Carmena R (2003) Abdominal obesity, insulin resistance, and metabolic syndrome in a southern European population. European Journal of Internal Medicine 14, 101-106.

Balkau B \& Charles M (1999) Comment on the provisional report from the WHO consultation. Diabetic Medicine 16, 442-443.

Balkau B, Vernay M, Mhamdi L, Novak M, Arondel D, Vol S, Tichet J \& Eshwege E (2003) The incidence and persistence of the NCEP (National Cholesterol Education Progam) metabolic syndrome. The French D.E.S.I.R. study. Diabetes Metabolism 29, 526-532.

Bonora E, Kiechl S, Willeit J, Oberhollenzer F, Egger G, Bonadonna R \& Muggeo M (2003) Prevalence, ancillary clinical features and cardiovascular disease in the metabolic syndrome: the Bruneck study. International Congress Series 1253, 13-17.

Carr D, Utzschneider K, Hull R, Kodama K, Retzlaff B, Brunzell J, Shofer J, Fish B, Knopp R \& Kahn S (2004) Intra-abdominal fat is a major determinant of the National Cholesterol Education Program Adult Treatment Panel III criteria for the metabolic syndrome. Diabetes 53, 2087-2094.

Cefalu W (2001) Insulin resistance: cellular and clinical concepts. Experimental Biology and Medicine 226, 13-26.

Chen W, Srinivasan S, Elkasabany A \& Berenson G (1999) The association of cardiovascular risk factor clustering related to insulin resistance syndrome (Syndrome $\mathrm{X}$ ) between young parents and their offspring: the Bogalusa Heart Study. Atherosclerosis 145, 197-205.

Cunnane S \& Griffin B (2002) Nutrition and metabolism of lipids. In Introduction to Human Nutrition, pp. 81-115 [M Gibney, H Vorster and F Kok, editors]. Oxford: Blackwell Science.

Diabetes UK (2004) Diabetes in the UK 2004, pp. 1-27. www.diabetes.org.uk/infocentre/reports/in the UK 2004.doc

Dowse G \& Zimmet P (1993) The thrifty genotype in noninsulin dependent diabetes. British Medical Journal 306, $532-533$
European Group for the Study of Insulin Resistance (2002) Frequency of the WHO Metabolic Syndrome in European cohorts, and an alternative definition of an insulin resistance syndrome. Diabetes Metabolism 28, 364-376.

Expert Panel on Detection, Evaluation, and Treatment of High Blood Cholesterol in Adults (2001) Executive summary of the third report of the National Cholesterol Education Program (NCEP) Expert Panel on Detection, Evaluation, and Treatment of High Blood Cholesterol in Adults (Adult Treatment Panel III). Journal of the American Medical Association 285, 2486-2497.

Ford E, Giles W \& Dietz W (2002) Prevalence of the metabolic syndrome amongst US adults: findings from the Third National Health and Nutrition Examination Survey. Journal of the American Medical Association 287, 356-359.

Ford ES (2004) The metabolic syndrome and mortality from cardiovascular disease and all causes: findings from the National Health and Nutrition Examination Survey II Mortality Study. Atherosclerosis 173, 309-314.

Grundy S (2004a) Metabolic syndrome: Part I. Endocrinology and Metabolism Clinics of North America 33, ix-xi.

Grundy S (2004b) Obesity, metabolic syndrome, and cardiovascular disease. Journal of Clinical Endocrinology and Metabolism 89, 2295-2600.

Haber E, Ximenes H, Procopio J, Carvalho C, Curi R \& Carpinelli A (2002) Pleiotropic effects of fatty acids on pancreatic beta cells. Journal of Cellular Physiology 194, $1-12$.

Hanson R, Imperatore G, Bennett P \& Knowler W (2002) Components of the Metabolic Syndrome and incidence of type 2 diabetes. Diabetes 51, 3120-3127.

Hills S, Balkau B, Coppack S, Dekker J, Mari A, Natali A, Walker M \& Ferrannini E (2004) The EGIR-RISC Study (The European group for the study of insulin resistance: relationship between insulin sensitivity and cardiovascular disease risk): 1 . Methodology and objectives. Diabetologia 47, 566-570.

Hu G, Qiao Q, Tuomilehto J, Balkau B, Borch-Johnsen K \& Pyorala K (2004) Prevalence of the metabolic syndrome and its relation to all-cause and cardiovascular mortality in nondiabetic European men and women. Archives of Internal Medicine 164, 1066-1076.

International Obesity Task Force (2004) IOTF Childhood Obesity Report, May 2004. http://www.iotf.org/media/IOTFmay28.pdf

Isomaa B, Almgren P, Tuomi T, Forsen B, Lahti K, Nissen M, Taskinen M \& Groop L (2001) Cardiovascular morbidity and mortality associated with the metabolic syndrome. Diabetes Care 24, 683-689.

James P (2004) Obesity: The worldwide epidemic. Clinics in Dermatology 22, 276-280.

Kohen-Avramoglu R, Theriault A \& Adeli K (2003) Emergence of the metabolic syndrome in childhood: an epidemiological overview and mechanistic link to dyslipidaemia. Clinical Biochemistry 36, 413-420.

Kraegen E, Cooney G, Ye J \& Fuler S (2002) Peroxisome proliferator activated receptors, fatty acids and muscle insulin resistance. Journal of the Royal Society of Medicine 95, 14-22.

Laaksonen D, Lakka H, Niskanen L, Kaplan G, Salonen J \& Lakka T (2002) Metabolic syndrome and development of diabetes mellitus: Application and validation of recently suggested definitions of the metabolic syndrome in a prospective cohort study. American Journal of Epidemiology 156, $1070-1077$.

Lakka H, Laaksonen D, Lakka T, Niskanen L, Kumpulsalo E, Tuomilehto J \& Salonen J (2002) The metabolic syndrome and total and cardiovascular disease mortality in middle-aged men. Journal of the American Medical Association 288 , 2709-2716. 
Lobstein T, Baur L \& Uauy R (2004) Obesity in children and young people: a crisis in public health. Obesity Reviews 5, 4-85.

Malik S, Wong N, Franklin S, Kamath T, L'Italien G, Pio J \& Williams R (2004) Impact of the metabolic syndrome on mortality from coronary heart disease, cardiovascular disease, and all causes in United States adults. Circulation 110, $1245-1250$

Nestel P (2004) Nutritional aspects in the causation and management of the metabolic syndrome. Endocrinology and Metabolism Clinics of North America 33, 483-492.

Ninomiya J, L'Italien G, Criqui M, Whyte J, Gamst A \& Chen R (2004) Association of the metabolic syndrome with history of myocardial infarction and stroke in the third national health and nutrition examination survey. Circulation 109, 42-46.

Palaniappan L, Carnethon M, Wang Y, Hanley A, Fortmann S, Haffner S \& Wagenknecht L (2004) Predictors of the incident metabolic syndrome in adults. Diabetes Care 27, 788-793.

Panagiotakos D, Pitsavos C, Chrysohoou C, Skoumas J, Tousoulis D, Toutouza M, Toutouzas P \& Stefanadis C (2004) Impact of lifestyle habits on the prevalence of the metabolic syndrome among Greek adults from the ATTICA study. American Heart Journal 147, 106-112.

Reaven GM (1988) Role of insulin resistance in human disease. Diabetes 37, 1595-1600.

Resnick H, Jones K, Ruotolo G, Jain A, Henderson J, Lu W \& Howard B (2003) Insulin resistance, the metabolic syndrome, and risk of incident cardiovascular disease in nondiabetic American Indians. Diabetes Care 26, 861-867.
Scuteri A, Najjar SS, Muller DC, Andres R, Hougaku H, Metter EJ \& Lakatta EG (2004) Metabolic syndrome amplifies the age-associated increases in vascular thickness and stiffness. Journal of the American College of Cardiology 43, 1388-1395.

Tan C, Ma S, Wai D, Chew S \& Tai E (2004) Can we apply the National Cholesterol Education Program Treatment Panel definition of the metabolic syndrome to Asians? Diabetes Care 27, 1182-1186.

van Oostrom A, Cabezas M \& Rabelink T (2002) Insulin resistance and vessel endothelial function. Journal of the Royal Society of Medicine 95, 54-61.

Vessby B, Uusitupa M, Hermansen K, Riccardi G, Rivellese A, Tapsell L, et al. (2001) Substituting dietary saturated for monounsaturated fat impairs insulin sensitivity in healthy men and women: The KANWU study. Diabetologia 44, 312-319.

Weiss R, Dzlura J, Burgert T, Tamborlane W, Taksali S, Yeckel C, et al. (2004) Obesity and the metabolic syndrome in children and adolescents. New England Journal of Medicine 350, 2362-2374.

Wilson P (2004) Estimating cardiovascular disease risk and the metabolic syndrome: a Framingham view. Endocrinology and Metabolism Clinics of North America 33, 467-481.

World Health Organization (1999) Definition, Diagnosis and Classification of Diabetes Mellitus and its Complications. Part 1: Diagnosis and Classification of Diabetes Mellitus, pp. 1-59. Geneva: WHO.

World Health Organization/Food and Agriculture Organization (2003) Diet, Nutrition and the Prevention of Chronic Diseases. WHO Technical Report Series no. 916. Geneva: WHO. 
https://doi.org/10.1079/PNS2005442 Published online by Cambridge University Press 